\title{
Moderate Monism, Sortal Concepts and Relative Identity
}

Coincidence (e.g., of a statue and the piece of bronze which constitutes it) comes in two varieties - permanent and temporary. Moderate monism (about coincidence) is the position that permanent coincidence, but not temporary coincidence, entails identity. Extreme monism (a version of which is stage theory (Sider 2001, Hawley 2001)) is the position that even temporary coincidence entails identity (those who deny that there are merely temporary coincidents are another sort of extreme monist, I shall not be considering this position in this paper) ${ }^{1}$. Pluralists are opponents of monism tout court. ${ }^{2}$ The intuitively obvious, commonsensical position (= my own position) is moderate monism. It is therefore important to see if it can be sustained.

I first outline the moderate monism position and compare and contrast it with other metaphysical positions with which it is often associated. I then indicate the arguments for moderate monism that seem to me most persuasive, drawing on earlier work of my own (Noonan1993) and Johnston (1992). Next I turn to three criticisms of moderate monism, by Jim Stone (2005a, 2005c), Eric Olson (2006 and 2007) and Penelope Mackie (2008 and unpublished). In responding to these criticisms I maintain (a) that sortal concepts satisfy de dicto modal principles that constrain the histories and spatiotemporal surroundings of the things falling under them and that may be thought of as specifying their criteria of identity, (b) that a distinction is required between restricted sortal quantification over and unrestricted quantification over the things falling under a sortal concept (between e.g., 'some statue is ...' and 'something is a statue and is ...') and (c) that reflecting on the arguments which enforce this distinction provides the best ground for accepting that 'identity is relative' in one sense familiar from the writings of Peter Geach (1980), namely that identity under a 
sortal concept at a time (expressible in the form 'is the same $S$ as at $t$ ') does not entail absolute, Leibnizian identity. I shall suggest that one way (not the only way) of combining these ideas is to defend a variant of stage theory which is a sort of synthesis of some of the ideas of Hawley (2001) and Sider (2001), but does not depart so far from standard perdurantism and which yields a variant on moderate monism which may be thought of as moderately extreme monism (see Noonan 1976).

I begin by outlining the moderate monist position.

According to the moderate monist if God creates ex nihilo (at $t 1$ ) a bronze statue and later (at $t 10$ ) annihilates it, destroying both the statue and the bronze of which it is composed (so we have a case of permanent coincidence - Scenario I), the statue and the piece of bronze are identical. If, however, God simply radically reshapes the bronze at $t 10$ (so that we have a case of same-origin temporary coincidence, as Mackie 2008 calls it - Scenario II), the statue ceases to exist and the piece of bronze survives, so despite their coincidence up to $t 10$ the statue and the piece of bronze are two things.

Since the statue in Scenario I could not have been radically reshaped without being destroyed, but the piece of bronze in Scenario I could, to conform to Leibniz's Law the moderate monist must accept that modal predication is 'Abelardian' (Noonan 1991), so that the reference of, e.g., 'could have been radically reshaped without being destroyed' is different when attached to 'the statue' and 'the piece of bronze'. One way of fleshing this out is to give a Lewisean counterpart-theoretic account of modal predication, according to which 'could have been radically reshaped without being destroyed' stands for the property has a statue counterpart which is radically reshaped and not destroyed when attached to 'the statue', but stands for the property 
has a piece of bronze counterpart which is radically reshaped but not destroyed when attached to 'the piece of bronze'. However, acceptance of the Abelardian character of modal predication, which is obligatory for the moderate monist (and the stage theorist) - unless, of course, he endorses a comprehensive Quinean scepticism about any grade of modal involvement beyond modality de dicto - does not require acceptance of Lewisean counterpart theory, or a fortiori, of Lewisean modal realism (see Gupta 1980).

Another position with which the moderate monist need not associate himself is perdurantism, or four-dimensionalism. In fact, there is a two-way logical independence. A moderate monist is not logically required to be a perdurantism (and might very reasonably not be) and a perdurantist might, with logical consistency (though some perversity), embrace pluralism.

To see the lack of necessary connection between moderate monism and perdurantism, or four-dimensionalism, reflect on the commitments of the latter.

The first is what John Hawthorne (2006) refers to as the doctrine of plenitude: every persisting object has an infinite number of temporal parts, at least one for each non-zero temporal interval in its history. ${ }^{3}$ The perdurantist may embrace what Hawthorne calls 'instantaneous plenitude', that every persisting object has a temporal part for each instant of its existence, or he may accept only what Hawthorne calls 'gunky plenitude' and be non-committal about instantaneous temporal parts. Either way, his ontology contains a great many things that are not parts on the standard, three-dimensional, pluralist position.

The perdurantist may also accept the doctrine of 'universalism', that every aggregrate of temporal parts, whether or not located in the history of what we would commonsensically think of as a single object, is an object. 
The typical perdurantist also appeals to his ontology to deal with Lewis's problem of temporary intrinsics (which, of course, Lewis put forward as an argument for perdurantism). If I am bent on Monday but straight on Tuesday I stand in the bent on (or at) relation to Monday and the straight at relation to Tuesday. According to the standard three-dimensionalist position that is all that can be said. But the perdurantist can say more. He can say that I am bent on Monday because my Monday temporal part possesses the property of being bent. The three-dimensionalist cannot say this because he does not recognise the existence of my Monday temporal part. So the three-dimensionalist has to accept that the state of affairs of my being bent on Monday is irreducibly relational. On the other hand, the perdurantist can accommodate Lewis's intuition that shapes are fundamentally non-relational properties and that persisting things stand in such relations as the bent at relation to times in virtue of their temporal parts possessing fundamental non-relational properties.

Of course, the perdurantist does not have to accept the Lewisean intuition of the fundamentality of the non-relational (or more precisely, of the non-time-indexed, since it is not relations as such Lewis thinks should not be regarded as fundamental, but relations to times). All he is committed to accepting is that, if I am bent on Monday, I coincide with something, my Monday temporal part, which has the property of coinciding with something which is bent on Monday. He does not have to accept that the temporal part is bent on Monday; much less that it is bent simpliciter (where this means more than that it is bent at some time or bent at every time it exists). (To see why the perdurantist might wish to reject the Lewisean intuition of the fundamentality of the non-time-indexed, consider the property of being conscious on 
Monday. Should we say that if I possess it this is in virtue of the fact that something else (a temporal part of me) is conscious on Monday, or is conscious simpliciter?)

The minimal perdurantist commitment, then, is to gunky plenitude, and so to an ontology significantly more extensive than that of common sense, and it should be clear that the moderate monist has no such evident commitment. His motivation is repugnance at the inflated ontology of the pluralist, which in itself can hardly incline him to endorse the perdurantist's plenitudinous ontology. Moreover, the moderate monist need not accept a plenitude of temporal parts in order to appeal to the Abelardian character of modal predication to resist the pluralist's argument from Leibniz's Law. The two are clearly separable (even though they are both embraced by Lewis).

Moderate monist need not be perdurantists, then, unless everyone needs to be. Equally, perdurantists need not be moderate monists. A perdurantist can accept that, whenever I exist, there is something coincident with me that exists only at that time, without regarding me as a mere aggregate of such temporal parts. Or he can say that the temporal parts of the statue and the permanently coincident piece of bronze are distinct - in virtue perhaps of modal differences between them, so the statue-at- $t 5$ and the piece-of-bronze-at- $t 5$ are distinct instantaneous objects that (permanently) coincide. Insofar as the perdurantist wants to emphasise analogies between time and space he should not adopt this view but it is logically consistent.

The argument for moderate monism should not then be that it is a consequence of perdurantism, since it is not. So what arguments are there for moderate monism?

Of course, moderate monism is a conjunctive thesis: that permanent coincidence is, but temporary coincidence is not, identity. So arguments for it have to 
rule out both the opposing positions, both pluralism and extreme monism. In this section I focus just on arguments against pluralism and defer discussion of extreme monism until later (though, as indicated, I am in fact a good deal less unfriendly to its stage-theoretic version than to pluralism).

The fundamental anti-pluralist intuition is an intuition of supervenience: there cannot be two purely material objects which in all actual, relational and nonrelational, past, present and future respects are microphysically indistinguishable - as the statue and the piece of bronze are in the permanent coincidence situation if they are not identical. But this is precisely what the pluralist denies, so how can we get beyond the clash of intuitions?

I think that there are two main lines of argument against pluralism.

First, while it may be disputable whether the statue and the piece of bronze in the permanent coincidence situation - call them, as usual, Goliath and Lumpl - are distinct objects, no one could accept that they are distinct statues. The pluralist has to say that despite having its entire history in common with Goliath, Lumpl is not a statue, and despite having its entire history in common with Lumpl, Goliath is not a piece of bronze (alternatively the pluralist can say that though Goliath and Lumpl are both statues and distinct objects they are not distinct statues, but no pluralist will say that). So the pluralist has got to deny that Lumpl is a statue and that that Goliath is a piece of bronze.

But consider the following proposition (adapted from Johnston 1992, see also Noonan 1993; I follow Johnston's numbering):

(8) If $y$ is a paradigm statue and $x$ is microphysically exactly like $y$ then $x$ is a statue. 
Goliath is a paradigm statue, and Lumpl is microphysically indistinguishable from Goliath, so, given (8), Lumpl is a statue. Hence, if they are distinct there must be not merely two coincident material objects where Goliath is, but two coincident statues. But this is intolerable; hence, given (8), Goliath and Lumpl cannot be distinct.

Although Johnston thinks that this is an impressive argument against pluralism, he thinks that it can be resisted, since it can be seen that (8) is false. (8) is false because if it were true the following would also be true:

(9) If $y$ is a paradigm statue and $x$ is an entity that differs from $y$ in any respect relevant to being a statue only very minutely, then $x$ is a statue.

But (9) is false, Johnston argues, since (10), below, is true:

(10) In the closest vicinity of any paradigm middle-sized material $F$ there are usually very many entities that differ only minimally from the paradigm in any respect.

Applying this principle to the case of Goliath/Lumpl, given (9) we must conclude that in the vicinity of Goliath there must be many statues, albeit highly coincident, almost completely overlapping. But this is false, hence, Johnston argues, (9) and hence (8) must be rejected.

Johnston thinks that what should replace (8) and (9) are:

(8') If $y$ is a paradigm statue and $x$ is intrinsically exactly like $y$ and $x$ is of the right category, i.e., not a mere quantity or piece of matter, then $x$ is a statue and:

(9') If $y$ is a paradigm statue and $x$ is an entity that differs from $y$ in any respect relevant to being a statue only very minutely and $x$ is of the right category, i.e., is not a mere quantity or piece of matter, then $x$ is a statue. 
I have doubts about these replacements, but it is clear that the following alternative weakenings of (8) and (9) are not cast into doubt by Johnston's argument:

(8*) If $y$ is a paradigm statue and $x$ is microphysically exactly like $y$ and $x$ does not merely partly overlap any statue then $x$ is a statue.

$\left(9^{*}\right)$ If $y$ is a paradigm statue and $x$ is an entity that differs from $y$ in any respect relevant to being a statue only very minutely and $x$ does not merely partly overlap any statue then $x$ is a statue.

But if $\left(8^{*}\right)$ is true Lumpl is a statue just as Goliath is.

And, of course, if $\left(8^{*}\right)$ and $\left(9^{*}\right)$ are acceptable so the still weaker:

$\left(8^{*}\right)$ If $y$ is a paradigm statue and $x$ is microphysically exactly like $y$ and $x$ does not merely partly overlap any statue and $\mathrm{x}$ is of the right category, i.e., not a mere quantity or piece of matter, then $x$ is a statue,

and:

$\left(9^{*}\right.$ ') If $y$ is a paradigm statue and $x$ is an entity that differs from $y$ in any respect relevant to being a statue only very minutely and $x$ does not merely partly overlap any statue and $x$ is of the right category, i.e., not a mere quantity or piece of matter, then $x$ is a statue.

Of course, $\left(8^{*}\right)$ does not entail that Lumpl is a statue, but as we shall see later it can be used in conjunction with the second main argument against pluralism to push the pluralist to further extremes.

So the pluralist must reject $\left(8^{*}\right)$. How?

Well, one thing that the pluralist can say is that $\left(8^{*}\right)$, like $(8)$, is false because something is a statue - an artwork - in virtue partly of its relational properties (Baker 1997). But it is obviously false that if $x$ is an $F$ in virtue partly of its relational 
properties and $y$ is intrinsically microphysically like $x$ and does not merely partly overlap $x$ then $y$ is an $F$.

This is correct. ( $\left.8^{*}\right)$ and (8) are obviously false, as Johnston notes, since whether something is a statue depends on its causal origin, at least. But since it is part of the story that Goliath and Lumpl have the same origin and all the same relational properties (expressible in microphysical terms) there is no (non-question-begging) response here for the pluralist. ${ }^{4}$

The second way the pluralist can resist accepting $\left(8^{*}\right)$ is by insisting that sortal concepts are constituted by persistence conditions which give necessary conditions of falling under them and that, in the case of the concept of a statue, one such persistence condition is: being incapable of being radically changed in shape. So Lumpl is not a statue and $\left(8^{*}\right)$ is false because Lumpl is capable of being rolled into a ball and not destroyed and no statue is. Later I will be arguing that it is not necessary to assume that sortal concepts involve de re persistence conditions of this type in order to distinguish them from non-sortal concepts and what is acceptable in the thought that they do can be made consistent with moderate monism. But for now all I want to emphasise is that if it is said that Lumpl is a piece of bronze and not a statue because it is capable of being rolled into a ball without being destroyed it cannot also be said that it is capable of being rolled into a ball and not destroyed because it is piece of bronze and not a statue. The pluralist who appeals to modal differences to explain why Goliath and Lumpl are of different sorts cannot say that their modal differences are explicable in terms of their different sorts.

The final possibility for the pluralist who wishes to reject $\left(8^{*}\right)$ then is just to say that the sortal difference between Goliath and Lumpl is primitive. No other difference between them explains why Goliath is a statue and Lumpl not, although 
there are other differences between them consequential on this difference, like the modal difference just noted, and other differences are possible because of this difference (it may be that the statue is admired and the piece of bronze not, that the statue is valuable and the piece of bronze not etc. (Fine 2003)). Not every difference between things can be grounded in some other difference, one must stop somewhere and in this case that is here. This seems implausible. It is plausible that the question 'In virtue of what is this object (which is in fact an electron) negatively charged?' may have no answer, but it does not seem plausible that the question 'In virtue of what is this object (which is in fact a statue) a statue?' should be similarly unanswerable.

At any rate, to reject the first argument against pluralism the pluralist must deny $\left(8^{*}\right)$ and to do so relevantly he must either accept that purely material entities of identical material constitution at all times can be distinct merely in virtue of differences in modal, dispositional or counterfactual properties or that purely material entities of identical material constitution at all times can be distinct merely in virtue of differences in sortal properties.

The second argument against pluralism I find impressive is that it entails a degree of ontological inflation far greater than that made evident by the case of Goliath and Lumpl.

Start with the thought that we employ a particular set of artefact concepts, but could have employed a slightly different set. Thus we talk, for example, of 'snowballs', where what is required for the persistence of a snowball is the persistence of a roughly spherical lump of snow. A snowball is destroyed once the lump is flattened into a disc shape.

Clearly, however, we could talk of 'snowdiscballs', where what is required for the persistence of a snowdiscball is less demanding; merely that the lump of snow 
remains either in a ball shape or a disc shape (see Sosa 1987). The concept of a snowdiscball is as legitimate as the concept of a snowball and, in fact, in many cases where a snowball is present there will also be present an all-times-coincident snowdiscball (in every case, that is, in which the snowball is not made from a previously disc shaped piece of snow or destroyed by flattening it into a disc shape). But to hold, in such a situation, that two, at-all-times-coincident, entities are present seems clearly absurd. It cannot be justified by insisting on the systematic reasons for distinguishing pieces of matter from the objects which constitute them, which Johnston gives as reasons for preferring his $\left(8^{\prime}\right)$ and (9') to (8) and (9). ${ }^{5}$ And, again, if we accept that in such a situation there are two coincident entities, we are bound to accept many more, for, once one gets the idea, it is very easy to invent other variations on the concept of a snowdiscball (Johnston 2006 has 'sporks' and 'foons'). So the point obviously generalizes to other artefact concepts and there seems no reason to reject its generalization to all concepts but an unacceptable anthropocentrism.

The position, then, is that if we insist on the standard, non-Abelardian, account of modal predication, which underpins the usual Leibniz's Law argument for pluralism, it will not be enough to allow that there is a systematic distinction between pieces of matter and the material objects they constitute; we will also have to accept that within the category of material objects constituted by pieces of matter it is possible for two distinct material objects to be at all times coincident, and in fact we will have to accept that not only can this be the case, but it is always the case whenever we are prone to speak of there being one material object of a certain sort, there are, in fact, very many, always coincident, material objects of similar sorts distinguished only by their modal, dispositional or counterfactual properties. Moreover, these entities will not merely be of similar sorts (snowballs and 
snowdiscballs) but of the same sort unless the doubly weakened version of (8), namely $\left(8^{*}\right)$ and its equivalents for other concepts are all relevantly false. I submit that accepting this is too high a price to pay just to preserve the standard account of modal predication. Yet once we reject that account we no longer have any good argument for non-identity even in the case of Goliath and Lumpl; we can, therefore, embrace monism without qualms.

III

I turn now to the arguments against moderate monism and begin with Jim Stone's (2005a, 2005c).

Stone argues that moderate monism is incoherent, employing an argument that Penelope Mackie (2007) has dubbed the 'modal dilemma'. His argument is that if the moderate monist accepts, as he must, the Abelardian account of modal predication, he has a problem explaining why in the same origin, temporary coincidence, scenario (Scenario II) the up-to time-t10-coincident statue and piece of bronze then go their separate ways.

It is natural to respond to this demand for explanation by appealing to a modal difference between the two: the statue does not survive radical reshaping because it cannot, whereas the piece of bronze can. Or, as Mackie (2007) puts it, it is natural to respond to the explanatory demand by appealing to the fact that in Scenario II:

(M3) The statue can survive being transformed is false, although

(M4) The piece of bronze can survive being transformed is true.

But if modal predication is Abelardian this apparent difference need not correspond to any genuine difference between the statue and the piece of bronze, 
since this difference in truth-value is compatible with the statue being the piece of bronze (as in Scenario I). But then it looks as if the mere fact that (M3) and (M4) differ in truth-value cannot explain why in Scenario II the statue and the piece of bronze go their separate ways.

Thus, it appears, the moderate monist faces what Mackie calls a modal dilemma. To account for the identity verdict in Scenario I he must accept that modal predication is Abelardian, but to endorse the intuition that the apparent modal difference between the up-to-t10-coincident statue and piece of bronze in Scenario II is explanatory of their future divergence he must regard this difference as a genuine one - which seems to require rejecting Abelardianism.

To see how the moderate monist can explain why the statue and the piece of bronze go their separate ways in Scenario II note first that, irrespective of one's view of modal predication, the fact that (M3) is false and (M4) is true in Scenario II cannot explain why the statue and the piece of bronze in fact go their separate ways, since although the fact that (M3) is false entails that the statue does not in fact survive reshaping, the fact that (M4) is true does not entail that the piece of bronze in fact does survive reshaping - since what can happen may or may not in fact happen.

The explanation of the divergence of the statue and the piece of bronze in Scenario II that the moderate monist can offer goes like this:

1) The statue is a statue

2) No statue can survive radical reshaping

So:

3) No statue does survive radical reshaping So:

4) The statue does not survive radical reshaping. 
But:

5) Necessarily, any piece of bronze survives radical reshaping in which all its matter is preserved in one coherent whole

6) The matter of the piece of bronze is radically reshaped but preserved in one coherent whole.

So:

7) The piece of bronze survives radical reshaping.

Therefore:

8) The statue and the piece of bronze go their separate ways.

In this explanation (2) and (5) are de dicto modal propositions which tell us something about the persistence conditions of statues and pieces of bronze. (1) and (6) are nonmodal claims about what actually happens. The proposition that the statue is not a piece of bronze (but see section IV below) is, of course, entailed by this explanation, but it does not have an explanatory role.

The obvious worry about this explanation is that it does not do sufficient justice to the intuition that the Scenario II statue does not survive reshaping because it cannot. The principle appealed to, to justify the claim that the statue cannot survive radical reshaping, is the de dicto modal principle, (2), that no statue can survive radical reshaping, that is, that necessarily, if something is a statue it does not survive radical reshaping. But we can introduce the predicate 'permanent bachelor' (Mackie's example in her 2007) with the obvious meaning and then there will be a de dicto modal principle analogous to (2) to the effect that no permanent bachelor can survive marriage. But it would be absurd to appeal to such a principle to explain why Dick, who, it turns out on his deathbed, was a permanent bachelor, never married when the opportunity presented itself. Analogously, then, why is it not absurd to explain the 
divergence of the statue and the piece of bronze in Scenario II by appeal to the $d e$ dicto modal propositions (2) and (5)?

What has to be explained about Scenario II is that the statue ceased to exist but the piece of bronze did not when the latter was flattened at $t 10$. Call this the Event. I explain the Event as follows. Someone beat the piece of bronze flat but did not break it up into little pieces (nor pour acid over it nor . .., i.e., no sufficient cause of its ceasing to exist occurred). So the statue constituted of the bronze was destroyed, but the piece of bronze, although reshaped, survived.

Now there are two further questions. Why did beating the bronze of which it was made flat cause the statue to cease to exist at $t 10$ ? And why did beating the bronze flat, but not breaking it up into bits etc., not cause the piece of bronze to cease to exist. I appeal to the de dicto modal principles (2) and (5) to answer these two questions. No statue can undergo radical transformation in shape, so one of the ways of destroying a statue is to radically reshape the matter of which it is composed. On the other hand, it is necessarily true that whenever a piece of bronze is such that the matter composing it is preserved in one coherent whole it continues to exist, so radically reshaping alone cannot destroy a piece of bronze.

The difference between this explanation of the Event and the suggested absurd explanation of permanent bachelor Dick's lifelong avoidance of marriage is straightforward. The statue in Scenario II is not identifiable in a way that makes a causal answer available to the question why, when the bronze composing it was radically reshaped, it did not undergo a radical transformation of shape (rather than cease to exist) - though, of course, there will be a causal answer to the question why it was destroyed. But on the other hand, any situation in which a man is a permanent bachelor is one in which he is identifiable in some way (e.g., as Mary's eldest brother) 
that allows the formulation of a question about him of the form 'Why did $X$ never marry?' to which there is a causal answer. ${ }^{6}$

I conclude that explaining why the statue and the piece of bronze in the sameorigin-temporary-coincidence scenario go their separate ways is no problem for the moderate monist. To do so he needs merely to appeal to factual claims and to de dicto modal propositions, so his distinctive Abelardian account of de re modal predication is not at issue.

This response to Stone's modal dilemma serves equally as a response to the 'paradox of increase', put forward by Eric Olson (2006 and 2007) as the best argument for immaterialism that there is. In fact, the possibility of increase is unproblematic for the moderate monist.

Objects with the same origin can cease to be coincident in two ways: one can continue to exist when the other ceases (as in the case of Goliath and Lumpl), or one or both can come to have a part the other lacks. When one of two coincident objects gains a part and the other does not, therefore, we merely have another example of a type of same-origin-temporary-coincidence scenario and we can anticipate that any apparent paradox can be disarmed by appeal to the same considerations that disarmed Stone's modal dilemma.

We can see how this plays out if we examine Olson's presentation of the paradox of increase more closely. He sets it out in entirely general terms, but it helps in thinking it through to have a concrete example in mind, so in what follows think of $A$ as a house, $B$ as a room which is added to the house after the initial construction and $C$ as the original structure before $B$ is added (or consider Kripke's example in his lectures on identity (unpublished) of the rootless plant (perhaps a tumbleweed - 
Johnston 2006: 667) consisting only of a stem until it grows a flower as a part). Here then is Olson's presentation of the paradox of increase (Olson 2007: 154):

Suppose we have an object $A \ldots$ and we want to make it bigger by adding a part $B \ldots$. Let us therefore conjoin $B$ and $A$ in some appropriate way. Never mind what this amounts to: let us do whatever it would take to make $B$ a part of $A$ if it ever can be. Have we thereby made $B$ a part of $A$ ? It seems not. We have only brought it about that $B$ is attached to $A$. ... we have rearranged $A$ 's surroundings by giving it a new neighbour, but we haven't given it a new part. If we have made $A$ a part of anything, we have made it a part of the thing made of $A$ and $B$ after our conjoining. But that thing ... didn't exist at all when we began ... or if it did ... it already had $B$ as a part.... It seems that nothing would ever give $A$ a new part.

Olson goes on to state this reasoning (2007: 159) in a way that makes its premisses explicit and lays out a range of possible solutions. Thus stated the reasoning has eight steps:

1) $A$ acquires $B$ as a part

2) When $A$ acquires $B$ as a part, it comes to be composed of $B$ and $C$ (= the rest of $A$ apart from $B$ )

3) $C$ does not acquire $B$ as a part

4) $C$ exists before $B$ is attached

5) $C$ coincides mereologically with $A$ before $B$ is attached

6) No two things can coincide mereologically at a time

So:

7) $C=A$

So: 
8) $A$ does not acquire $B$ as a part (from (3) and (7))

- contradicting the original assumption (1).

One way of resisting this argument, of course, is to deny (7), and hence (6). This is what the moderate monist (and, of course, the pluralist) does; he says that before $A$ acquires a new part it coincides with but is distinct from $C$, which ends up as a part of $A$. Olson responds (2007: $161-2$, see also 2006: $407-8$ ):

But if $A$ got bigger why didn't $C$ get bigger too? ... A but not $C$ has the capacity to grow by gaining $B$ as a part.... This is surprising. $A$ and $C$ are exactly alike before the attachment.... There is difference that could account for their differing capacity to acquire parts... We might try to explain it in terms of a difference in kind. $A$ can acquire new parts because it is a [house/plant] ... a thing of some 'mereologically inconstant' kind, $C$ cannot change its parts because it is [not]... But this is little help.... What is it about $A$ that makes it a [house/plant]? ... Ordinarily we expect there to be a physical difference between [houses/plants] and other things.... But there is no such difference between $A$ and $C$.... It looks as if what makes $A$ a [house/plant] is nothing more than what sort of thing it can survive ... it is a [house/plant] because, in addition to having all the right physical properties (which $C$ shares), it can also gain new parts.... Coincidentalists [i.e., pluralists and moderate monists] will apparently have to say that there is no explanation of why $A$ but not $C$ can gain new parts.... $A$ 's capacity and $C$ 's incapacity to gain new parts are basic properties of them ... we cannot explain their having these properties in terms of other properties, in the way that we can explain why an object is fragile in terms of the way its particles are bonded together. 
These considerations are evidently the same as those lying behind Stone's modal dilemma and the moderate monist response is the same. Of course, for their part, pluralists will see no force in Olson's argument since it is essential to their position that even permanently coincident things can differ in their capacities. So from their point of view it can hardly be 'surprising' that merely temporarily coincident things can so differ also. They have already swallowed the camel and need not strain at the gnat. The moderate monist will respond as follows. A house can be made bigger by appropriate building work just as a piece of bronze can be radically reshaped. There is a de dicto modal principle that specifies part of the persistence conditions for houses analogous to the de dicto principle, (5), employed in the explanation of the divergence of the statue and the piece of bronze at $t 10$ in Scenario II. A room cannot be made bigger by the sort of building work in question (it can be made bigger by building work of a different sort, of course). Again this is merely a de dicto modal principle, analogous to the de dicto modal principle, (2), about statues, so there is no more a puzzle about how the house is extended though the room is not than there is about how the piece of bronze undergoes radical reshaping though the statue does not. (Mutatis mutandis, there is no more a puzzle about how Kripke's plant comes to have a flower as a proper part though the stem does not.)

And surely this is exactly what we should expect. If someone asks 'Why was Goliath destroyed at $t 10$ ?', a sensible answer would be, for example, 'It was beaten shapeless with a hammer?' (Or, rather, this is an answer to the question 'How?'; an appropriate answer to the 'Why?' question might be: 'Because its owner wanted to reuse the bronze to make a different statue.') But if the response now is, 'I know it was beaten shapeless with a hammer, but why did beating it shapeless with a hammer destroy it?' the only appropriate reply is to say that doing that sort of thing to a statue 
is just what we call destroying it (it is a constraint on the history of anything that is correctly called a statue that it not undergo radical deformation in shape). Similarly, if someone asks why the room $C$ was not enlarged when the house $A$ was extended a sensible reply would be to point to the sort of building work done, which did not constitute what we call 'enlarging a room'. If the response is now 'I know that that sort of work was done, but why was carrying it out not enlarging the room (though it did constitute extending the house)?' the only appropriate reply to is repeat that doing that sort of building work is just what we call 'extending a house' and do not call 'enlarging a room'. Given that $C$ is a room, therefore, there is no more mystery about why it is not extended though $A$ is than about why Goliath is destroyed when the bronze is hammered shapeless.

The de dicto modal principles employed in these explanations can be thought of, as I have said, as specifying persistence conditions for things of the sorts in question, or again, they may be thought of as specifying criteria of identity for things of these sorts. Staying with the example of statues and pieces of bronze, we have seen two types of persistence conditions in the discussion above.

The principle that no statue can undergo radical reshaping can be expressed as follows

(S) Necessarily, if $x$ is a statue then if the matter that constitutes $x$ at $t$ is radically reshaped at $t$, then $x$ ceases to exist - this specifies a 'passing away' condition for statues (this terminology comes from Mackie (unpublished)).

The principle that any piece of bronze must survive radical reshaping in which all its matter is preserved in one coherent whole can be expressed as: 
(P) Necessarily, if $x$ is a piece of bronze then if the matter that constitutes $x$ at $t$ is radically reshaped at $t$ but preserved in one coherent mass, $x$ survives - a 'preservation' condition for pieces of bronze.

The reason why sortal concepts are governed by such conditions is that they constrain the histories and spatiotemporal surroundings of the things they apply to, and such constraints can always be expressed in the form:

Necessarily, if $x$ is an $S$ then if $x$ exists at $t$ and $t^{\prime}$ then $R x t t^{\prime}$ or in the form:

Necessarily, if $x$ is an $S$ then if $R x t t^{\prime} x$ exists at $t$ and $t^{\prime}$. Thus the 'passing-away' condition for statues is entailed by a principle of the first form (stating that a statue cannot have radically different shapes at different times) and the 'preservation condition' for pieces of bronze is entailed by a principle of the second form (stating that if the matter composing a piece of bronze is in one coherent mass at both of two times, whatever shape it is in, the piece of bronze exists at both times).

Principles of these forms lay down necessary conditions for being a thing of sort $S$ and a specification of the totality of such conditions is a specification of the persistence conditions, or the criterion of diachronic identity, for things of that sort. What distinguishes sortal concepts from non-sortal concepts (even ones that necessarily apply to a thing at any time it exists, like being a permanent bachelor) is that they are governed by such de dicto modal principles.

It follows that questions about criteria of identity over time are misunderstood if they are thought of as questions about identity. Rather they are questions about the conditions of membership of sortal kinds. The problem of statue identity over time, 
for example, can be formulated in a pair of questions as follows, without mention of identity:

(Q1) What conditions $C$ satisfy the following schema: (SC1) If $x$ is a statue then if $x$ exists at $t$ and $t^{*}, C x t t^{*}$ ?

(Q2) What conditions $C$ satisfy the following schema: (SC2) If $x$ is a statue then if $C x t t^{*} \mathrm{x}$ exists at $t$ and $t^{*}$ ?

A solution to the problem, i.e., an account of statue identity over time, will then take the following form:

All and only the following conditions satisfy schema (SC1): [LIST] and all and only the following conditions satisfy schema SC2): [LIST].

Of course, in answering these questions we only specify some of the necessary conditions of statuehood. One other type of necessary condition can be thought of as a synchronic constraint, capturable in the form:

Necessarily, if $x$ is a statue then if $x$ exists at $t, F x t$ where ' $F$ ' represents an expression for a non-historical property, i.e., one entailing nothing about the past or future.

In addition, the general problem of the criterion of identity for statues, asked without reference to time, can be formulated by asking for a specification of the relation $R$ satisfying the condition:

(1) Necessarily, if $x$ is a statue and $y$ is a statue then ( $x=y$ iff $R x y)$.

(1) is equivalent to the conjunction of:

(1a) Necessarily, if $x$ is a statue then $R x x$

and

(1b) Necessarily, if $x$ is a statue then if $y$ is a statue and $R x y$ then $(x=y)$, 
Together these imply that necessarily any statue is (identical with) the statue $R$-related to it. They thus give a sufficient condition for identity with any statue by giving a necessary condition of statuehood.

Thus all intelligible questions about statue identity are equivalent to questions about the necessary conditions for being a statue. And, in general, all intelligible questions about the identity of things of sortal kind $S$ are equivalent to questions about the necessary conditions for being a thing of kind $S$ (though, of course, intelligible questions about necessary conditions for being an $S$ are not all equivalent to questions about the identity conditions of things of kind $S$ ). Answers to these questions are what one is seeking when one enquires about the conditions of $S$-identity over time.

\section{IV}

I claim, then, that the moderate monist can answer the objections of Stone and Olson. Now I turn to Mackie's objection (Mackie 2008).

The response to Stone and Olson requires that whether a sortal concept applies to a thing depends on its total history, past, present and future, and spatiotemporal surroundings. But Mackie objects that this is implausible. Whether something is a statue, for example, at a time plausibly depends on its past, but it cannot depend on its future. The concept of a statue is not future-reflecting, like the concept of a future President, say, which applies to someone at a time in virtue of facts rooted outside that time. But, then, she argues, moderate monism must be incorrect. Since Lumpl is distinct from Goliath in the same-origin-temporary-coincidence scenario it is not a statue, even before Goliath's demise (there are not two statues there then). So, since the same-origin-permanent coincidence situation differs only with respect to future events, Lumpl is not a statue there either. But Goliath is. So they are two, not one. Pluralism is vindicated. 
Mackie also appeals to the contention that sortal concepts are not futurereflecting to challenge the first of the arguments given in Section II above against pluralism. The argument was based on the plausibility of the following sufficient condition for being a statue:

(8*) If $y$ is a paradigm statue and $x$ is microphysically exactly like $y$ and $x$ does not merely partly overlap any statue, then $x$ is a statue.

But Mackie argues that since sortal concepts are not future reflecting $\left(8^{*}\right)$ is no more plausible than:

(8*B) If $y$ is a paradigm statue and $y$ begins to exist at $t$ and $x$ begins to exist at $t$ and $x$ is microphysically exactly like $y$ from $t$ up to some later time $t$ ' and $x$ does not merely partly overlap any statue from $t$ to $t^{\prime}$, then $x$ is a statue. But she says, moderate monists must reject $\left(8^{*} \mathrm{~B}\right)$, on pain of making the statue and piece of bronze identical in the same-origin-temporary-coincidence scenario. So the moderate monist's appeal to $\left(8^{*}\right)$ is undermined.

One way the moderate monist can respond to all this is by rejecting the claim that sortal concepts are not future-reflecting. He can agree that I do not need foresight to know that there is a statue before me, and that I can know of what is before me that it coincides with a statue without knowing its future - and so he can agree that in these respects the concept of a statue is unlike the concept of a future President whilst insisting that in the strict sense Mackie's argument requires not to be the case, sortal concepts are future-reflecting. He can say that the constraints on the history of a statue given by its persistence conditions entail that a thing is not a statue unless it has both a certain kind of past, present and future and a certain kind of spatiotemporal environment, so in the same-origin-temporary coincidence scenario Lump is not a statue and Goliath is not a piece of bronze. ${ }^{7}$ However, I think it must be granted that it 
is acceptable to say of Lump before $t 10$, even in the temporary coincidence scenario, in virtue of its coincidence with Goliath, that it is a statue. So I think that the moderate monist needs to make room for Mackie's insistence that sortal concepts are not futurereflecting, even in the strict sense. What follows?

First, it follows that whether we are in the permanent-coincidence or temporary-coincidence scenario, Lumpl is a statue before $t 10$. So in the temporarycoincidence scenario there are two objects present before $t 10$ each of which is a statue then. Are there two statues there? Not unless we count by identity. So the moderate monist can simply deny that we do. In other words the moderate monist can simply take a leaf out of the relative identity theorist's book. Entities are to be counted as two statues, he can say, when both are statues and are not the same statue. But though when coincident Goliath and Lumpl are both statues they are then the same statue, so they are to be counted as one statue. They are the same statue because the relation we express in English with the form of words 'is the same statue as at time $t$ ' is a relative equivalence relation, not an absolute equivalence relation.

In fact, we can now see that the same-origin-temporary-coincidence scenario is just an example of precisely the type of situation to which relative identity theorists typically appeal in support of their position.

Consider Geach's unlucky cat, Tibbles, and its tail complement, Tib. ${ }^{8}$ Tibbles is sitting comfortably on the mat. And Tib is there too, occupying a smaller region. Some relative identity theorists (and others, for example, Chisholm 1986) are prepared to argue as follows: 'There is one cat on the mat. Tib is on the mat. Tibbles is on the mat. Tib is a cat. Tibbles is a cat. So Tibbles is (one and) the same cat as Tib. But Tib is not (identical with) Tibbles (it is smaller). So objects can be the same cat 
without being numerically identical. Being the same cat as at a time is a relative identity relation.'

But there is an easy response to this argument, namely that the concept of a cat is maximal; no cat is a proper part of a cat.

The relative identity theorist can avoid this response by extending the story by supposing that Tibbles' tail cut off. After the amputation Tib is wholly coincident with Tibbles, so that appeal to the maximality requirement on the concept of a cat fails. But the relative identity theorist's opponent can plausibly say that Tib is not a cat even after the amputation, because it has the wrong past history.

But the relative identity theorist can avoid this rejoinder by suggesting a timereversed variant of the case of Tib and Tibbles, in which we begin with a tailless cat and graft on a tail - in other words a same-origin-temporary-coincidence case of the same type as the Goliath/Lumpl example, or Olson's example of (house) $A$ and (room) $C$. Now the opponent of relative identity faces a hard set of choices. He can deny that both Tib and Tibbles exist before the grafting. Or he can accept that the concept of a cat is future-reflecting. Or he can join the pluralist in denying that there need be any actual microphysical difference, relational or non-relational, past, present or future between a cat and something which is not a cat - which takes us back over old ground.

It is not surprising then that the moderate monist's position, when developed in the most straightforward way to meet Mackie's objection whilst acknowledging her insight, leads to an acceptance of relative identity. ${ }^{9}$

But Mackie's objection can be pressed further. I have claimed that the moderate monist can say that Goliath and Lumpl are the same statue before $t 10$ in the temporary coincidence scenario. But we can speak, and I have been speaking, of the 
statue in the scenario, and the (statue shaped and sized) piece of bronze. How are these definite descriptions to be understood?

At this point the moderate monist must take another leaf out of the relative identity theorist's book, and distinguish between restricted sortal quantification and unrestricted quantification over things falling under a sortal concept. The de dicto persistence conditions governing the concept of a statue define a sortal kind to which in the temporary coincidence scenario Goliath but not Lumpl belongs. These persistence conditions make reference to multiple times, which is why an object's being of the sortal kind entails that it has a certain kind of history, and why properties had at times other than $t$ by an object existing at time $t$ are relevant to determining whether it is of this sortal kind. It is things of this sortal kind we quantify over when we use the quantifying expressions 'some statue' and 'every statue' (mutatis mutandis, 'some piece of bronze' and 'every piece of bronze'). And it is these quantifying expressions that figure in the appropriate Russellian expansion of the definite descriptions mentioned above. So the description 'the statue in such and such a place at $t 5^{\prime}$ uniquely denotes Goliath even though Lumpl is there and is also, before t10, a statue.

As I said, the distinction between restricted sortal quantification and unrestricted quantification over things falling under a sortal concept is a familiar part of the relative identity theorist's package, but in a moment I want to show how it naturally emerges in another framework, namely, that of the stage-theorist. Before coming to that, however, I want first to explain how it is a necessary part of the moderate monist's position even if relative identity is rejected.

Return to the permanent coincidence scenario. The moderate monist says that in this situation Goliath is Lumpl. So he has to accept that modal predication is 
Abelardian. So he is able to deny that Lumpl would be destroyed if rolled into a ball whilst acknowledging that Goliath would be destroyed if rolled into a ball. Can he also endorse the universally quantified proposition that any statue would be destroyed if rolled into a ball (with the exception of statues, we better add to be strict, originally created to be ball shaped)?

An argument that he cannot goes as follows. According to the moderate monist Lumpl is Goliath in the permanent coincidence situation. So it is a statue. So if the moderate monist accepts that anything that is a statue would be destroyed if rolled into a ball he must accept that Lumpl would be destroyed if rolled into a ball. But he doesn't. So he must deny that anything that is a statue would be destroyed if rolled into a ball. So he must deny that any statue would be destroyed if rolled into a ball. The only response available to the moderate monist, if he wishes to endorse the commonsensical proposition that any statue would be destroyed if rolled into a ball, is to distinguish this from the stronger proposition that anything that is a statue would be destroyed if rolled into a ball. But this is to distinguish (where ' $S$ ' is a sortal term) between a proposition of the form 'Every $S$ is ...' and one of the form 'Everything, if it is an $S$ is ...' (where '...' represents a modal or dispositional predicate), which is precisely to distinguish restricted sortal quantification from unrestricted quantification over things that satisfy a sortal concept. (The need for this distinction for the moderate monist is implicitly noted by Lewis in his paper 'Counterparts of Persons and their Bodies' (1971), where he points out that on his account of modal predication, even if everybody (i.e., every person) is his body and conversely, every body is a person, 'Everybody might have been a disembodied spirit' does not have the same truth-conditions as 'Every body might have been a disembodied spirit'; consequently the former cannot be equivalent to 'Everything, if it 
is a person, might have been a disembodied spirit', nor the latter to 'Everything, if it is a body, might have been a disembodied spirit'.)

Now I need to tie up some loose ends. I agreed with Mackie that sortal concepts are not future-reflecting, but now we have a sense in which they are. Lumpl is a statue before $t 10$ in the temporary-coincidence scenario, but it does not fall within the range of the quantifying expressions 'some statue' and 'every statue' that must be used in the appropriate Russellian account of the uniquely denoting definite description 'the statue in such and such a place before $t 10$ '. So Lump does not fall under the predicate 'is identical with some statue', when 'is identical with' denotes numerical identity and 'some statue' is the first of these quantifying expressions. So this predicate is future-reflecting, and given that 'is' can mean 'is numerically identical with', 'is a statue' is therefore ambiguous. ${ }^{10}$

I come now to the second loose end. Evidently, with the distinction now made I cannot endorse the de dicto modal principles employed previously in responding to Stone and Olson, but the acceptable modal principles are the ones got by replacing, in $(\mathrm{S})$ and $(\mathrm{P})$, 'if $x$ is a statue then ...' and 'if $\mathrm{x}$ is a piece of bronze then ...' by 'for every statue $x$ ' and 'for every piece of bronze $x$ ', understood as explained above. (Similarly, in the formulations, (Q1) and (Q2), of the problem of statue identity over time, the clause 'if $x$ is a statue then' in (SC1) and (SC2) must be replaced by 'for every statue $x, \cdot)^{11}$

Note also that within the present framework, as well as these de dicto modal principles, the moderate monist can also endorse a set of de re modal principles which are plausibly partly constitutive of our grasp of sortal concepts, such as:

Any statue would be destroyed if rolled into a ball Any piece of bronze would survive if rolled into a ball. 
The moderate monist can also endorse the following stronger principles, which are, however, ones that anti-essentialists, like Mackie (see Mackie 2006 and unpublished), would reject (though Lewisean anti-essentialists could accept):

No statue could survive if rolled into a ball

Any piece of bronze must survive if rolled into a ball. ${ }^{12}$

Finally, I want to explain how the present development of moderate monism can be seen as a plausible modification of stage theory if a four-dimensional ontology is assumed.

Recall first the distinction between standard perdurance theory and stage theory. For perdurance theorists statues and pieces of bronze are summations of stages, which may share parts. A statue is a maximal summation of stages linked by the statue unity relation. A piece of bronze is a maximal summation of stages linked by the piece of bronze unity relation. So whether something is (identical with) a statue depends on its future and spatiotemporal surroundings as well as its past and present. It follows that it no more makes sense to ask when something is a statue than it makes sense to ask where something is a house. This is how the perdurantist is able to satisfy the desideratum that sortal concepts are not time-indexed (do not express relations to times).

The stage theorist maintains, in opposition to the perdurantist, that statues and pieces of bronze are not maximal summations of stages linked by unity relations, but are themselves stages. Statues are stages, which is to say, (some) stages are statues. So at any time at which a statue and a piece of bronze coincide there is a genuine numerical identity between something that is a statue and something that is a piece of bronze: something is both a statue and a piece of bronze. An advantage that the stage theorist claims for his account is that it provides the right bearers for Lewis's 
temporary intrinsics. If I bend the statue and first straighten it out (let's suppose that this much distortion is consistent with the artist's creative intentions) then, Lewis says, there has to be something that is bent simpliciter and something that is straight simpliciter. But the endurantist who rejects plenitude cannot recognise such an object; he just recognises the enduring statue, which stands in the bent at relation to one time and the straight at relation to another. This, Lewis claims, is an argument for perdurantism. But if so, the stage theorist claims, it is an even better argument for stage theory, since he can capture, as the perdurantist cannot, the intuition that the thing that is bent simpliciter is a statue. The stage theorist will therefore be happy to say that at every moment before $t 10$ in the temporary coincidence scenario the piece of bronze is a statue and the statue is a piece of bronze, since every one of the coincident stages before $t 10$ is both a statue and a piece of bronze. ${ }^{13}$

The problem for the stage theorist is to explain why I have only ever shared my house with three cats, given that I have shared my house with an infinite number of cat stages (of course, he also faces the problem of explaining why I have shared my house with more than one cat given that 'I' denotes a present instantaneous stage, but, as is familiar, he solves this problem by appeal to an Abelardian temporal counterpart theory). One plausible line suggested by Hawley's discussion (2001:62) is to say that when counting cats we do not count by numerical identity, but by the cat unity relation, i.e., that relation which holds between two cat stages (cats) when, as the perdurantist would say, they are stages of the same cat. But since cat stages are cats, it is plausible to suppose that we count them as the same only when they are the same cat; in which case we must take it that 'is the same cat as' denotes, not numerical identity, but the cat unity relation (which, however, holds between simultaneous cat stages only when they are numerically identical -setting aside time-travelling cats). ${ }^{14}$ 
Another way of responding to the problem of counting across time, suggested by Sider's discussion (2001:197), is to say that sometimes, when we quantify over cats, we quantify not over cat stages (though they are cats), but over maximal summations of cat stages related pairwise by the cat unity relation. Understanding my assertion that I have only ever had three cats in terms of such quantification gets the truthconditions right.

These suggestions by Hawley and Sider are complementary. Stage theorists need both. They need quantification over summations as well as stages because they need to account for the function of such definite descriptions as 'the cat I lived with in 2001 and 2005' (I had two cats in 2001, one died, and I got another in 2002, which, along with the remaining cat, I still had in 2005). And stage theorists need to recognise that 'is the same cat as' denotes the unity relation for cats, rather than numerical identity, in order to avoid the implausibility of saying that though you have only ever owned one cat, you have owned infinitely many things, each of which was a cat and no two of which were the same cat.

At any rate, it is easy to see how the moderate monist can employ the stage theorist's ideas, modified in the way suggested, if he accepts the plenitudinous ontology common to the perdurantist and stage theorist. His account will still be distinct from that of an extreme monist (we can describe it as moderately extreme monism), since, though he will recognise a strict identity at any moment before $t 10$ in the temporary coincidence scenario between something which is correctly describable as a statue and something which is correctly describable as a piece of bronze, he will be able to deny that the statue is identical with the piece of bronze. And, of course, the arguments against pluralism and the responses to the objections to moderate monism put forward by Stone, Olson and Mackie will remain in force. 
${ }^{1}$ This denial is a consequence of compositional nihilism, which allows the existence only of simples, and of the dominant kinds theory (Burke 1984, Rea 2000). Both views are implausible. The former denies for no good reason the Moorean fact that complex objects exist. The latter denies that sortal concepts like 'statue' and 'piece of bronze' have the persistence conditions we think they have.

${ }^{2}$ The terminology comes from Fine (2003), with some modifications, Mackie (2008) calls what I call moderate monism 'intermiediate monism'.

${ }^{3} X$ is a temporal part of $y$ at $t$ if and only if $x$ coincides with $y$ at $t$ and $x$ exists only at $t$. One thing coincides with another at a time just in case the first then overlaps everything that is a part of the second at the time and the second then overlaps everything that is part of the first at the time. One thing overlaps a second at a time iff they share a part at the time. One thing is a temporal part of another iff it is a temporal part of it at some time (so temporal parthood is explained in terms of temporary parthood). I am a temporal part of myself. And if a piece of bronze is made into a statue, which is subsequently destroyed without repair or replacement of parts, the statue is uncontroversially a temporal part of the piece of bronze (it is not uncontroversially a temporary part of the piece of bronze, since if it is, it is a temporary proper part of the piece of bronze, which it cannot be if one thing is a temporary proper part of another at a time only if there is then a part of the second which the first does not then overlap). Given this definition, then, the difference between the endurantist or three-dimensionalist and the perdurantist cannot just be that the latter accepts the existence of temporal parts.

${ }^{4}$ In fact, Baker's own objection to the argument appears to be rather that Lumpl, although a statue, is so derivatively, and so is not a distinct statue from Goliath (Baker 
1997:604). If I understand this it involves accepting what I said earlier no pluralist could accept, that though Goliath and Lumpl are both statues and distinct (i.e., nonidentical) objects, they are not distinct statues, but the same statue. But since Baker denies that Lumpl is non-derivatively a statue she faces the same problems in explaining why this is so that the standard pluralist does in explaining why Lumpl is not a statue at all. Why are $\left(8^{*}\right)$ and $\left(8^{*}\right)$ false, except for reasons that have no bearing on the argument against the pluralist, when 'statue' is read as 'non-derivative statue'?

${ }^{5}$ The point that the pluralist is committed to distinct but at all times coincident artefacts can be made without appeal to the manufactured concept of a snowdiscball. Consider the familiar concepts of a house and a room. Suppose I build a one-roomed house, with the intention of extending it later, but never do. The house could have been enlarged into (or originally built as) a many-roomed mansion, in which case the room would have become (or always have been) a proper part of it. So the pluralist must distinguish the two (see further the discussion of the paradox of increase below, or consider Lewis's example of GWR and GWR- (1986) or Kripke's example of the rootless plant and its stem in his unpublished lectures on identity, or again, think of Russell's yacht, which might have been (all along) larger than it was). Note that two forms of pluralist argument can be distinguished. In the example of the permanently coincident house and room one form of argument is: 'The house could have begun as a one-room structure and subsequently been extended to a many-roomed mansion. The room could not have had this history. So the house and room are distinct.' The second form of argument is either (i): 'The house could all along have been a manyroomed structure. The room could not. So the house and room are distinct' or 
alternatively (ii) 'The house would have been all along a many-roomed mansion if such and such building work had been done originally. The room would not, even if this work had been done. So the house and the room are distinct'. Pluralists must regard both forms as valid. They can perhaps deny the soundness of some arguments of the second form by insisting on the necessity of origin. I think pluralists should deny the soundness of arguments of the second form even if they accept the soundness of those of the first form. It is a step too far to say that even ignoring what is the case at other times there must be a multitude of coincident things existing at a time just because it is correct to say that one thing existing at that time could, at that time, have been differently sized or shaped and a differently identified coincident thing existing at that time could not. Of course, as a monist I deny the validity of both argument forms.

${ }^{6}$ As Mackie points out (2007), this difference is related to the following fact about permanent bachelors: when a man marries, no permanent bachelor goes out of existence, and the 'coincidence' between a permanent bachelor and a man (unlike the coincidence between a statue and a piece of bronze) can never be merely temporary. ${ }^{7}$ This is to endorse E.J. Lowe's claim (2002: 371) that '[ $\left.\mathrm{t}\right]$ here is absolutely no mystery as to how [the temporarily coincident lump and statue] get to be of different kinds and have different identity conditions [before $t 10$ ] even though they are "materially indiscernible" [before $t 10]$ ': the explanation is that these differences are ones which turn in part on 'how the world is at [other] times.' Lowe suggests that only victims of the 'cinematographic fallacy' will resist this. The cinematographic fallacy is the idea that any qualitative differences between two objects at a moment of time $t$ must in principle be revealed by instantaneous 'snapshots' of these objects at $t$. Lowe 
thinks that the cinematographic fallacy lies behind objections to constitutionalists, i.e., pluralists, like himself. But if, as Lowe suggests, the cinematographic fallacy is the crucial flaw in the arguments of opponents of constitutionalism, the position he should endorse is not pluralism but moderate monism.

${ }^{8}$ What is Tib? Tib is a certain bodily part of a cat, like a tail, leg, whisker or head. We can run the Tib/Tibbles arguments taking Tib to be a cat's head, in fact. (Animals have been decapitated in experiments and their heads kept alive, though the subjects of these experiments were not cats but, as Tibbles would be pleased to know, dogs. In C.S. Lewis's novel, That Hideous Strength, the leader of the wicked organization Ransom fights is always referred to, it turns out significantly, as 'The Head'.)

${ }^{9}$ The pluralist need not reject this reasoning. In fact, extant pluralists should welcome it. From their point of view, to say that moderate monists should accept relative identity is just to say that one absurdity entails another.

${ }^{10}$ So if 'is a non-statue' is defined to be true of anything not satisfying the predicate 'is identical with some statue' it follows that something which is a non-statue is a statue. If this is an objection it is not one that standard pluralists can make. Ever since Wiggins's first book (1967) their position has recognised that it is acceptable to say of an object like Lumpl, temporarily coincident with a statue, that it 'is' a statue and they posit an 'is' of constitution to explain this. So they too are committed to the ambiguity of 'is a statue' and, with the definition of 'is a non-statue' just given, to accepting that there is a true reading of 'something which is a non-statue (e.g., Lumpl) is a statue'. It would be convenient for the pluralist if it was not acceptable to say before $t 10$ that Lumpl was a statue. But it is. 
${ }^{11}$ Using 'is a statue' in the sense in which Lumpl is a statue (before $t 10$ ) there are two possible temporally unqualified meanings: ' $x$ is a statue at some time' and ' $x$ is a statue whenever it exists'. On neither interpretation are $(\mathrm{S})$ and $(\mathrm{P})$ true. Of course, they are true if 'is a statue' is read as meaning 'is identical with some statue'.

${ }^{12}$ The difference between these two anti-essentialists is this. Lewis can hold that in every context 'I might have been a poached egg' is false, notwithstanding that I have poached egg counterparts, because the immediate context provided by the personal pronoun as the subject of the sentence always determines, whatever the other features of the context, that the personal counterpart relation is selected to interpret the modal predicate. Mackie has to hold that there are contexts, possibly philosophical discussions, in which all possibilities whatsoever are relevant and in such contexts 'I might have been a poached egg' is true.

${ }^{13}$ Another point in favour of the stage theory is that it can accommodate the intuition that continuants, for example cats, are wholly present whenever they are present, in the sense that whenever a cat exists it then possesses features intrinsic to the time such that their instantiation guarantees the existence at that time of a cat (even if a very short-live one) which has no temporal part located at any other time, that is, that the existence of a cat at a time is a 'temporally local' state of affairs (Shoemaker 2007:99). By contrast, a cat is not in a corresponding sense wholly present wherever it is; its existence there is not 'spatially local'. However, Shoemaker just sees this contrast as an argument against perdurantists; he does not consider stage theory. ${ }^{14}$ What if we do not set aside time-travelling cats? Then it still holds that the cat unity relation cannot hold between distinct simultaneous cat stages given the definition in note 3 of a temporal part (or stage). If Tibbles travels back in time to an earlier 
moment of his life, $t$, there is a single temporal part of Tibbles at $t$, which is not a cat, but has two distinct parts, at places $p 1$ and $p 2$, each of which is a cat. These two parts are the same cat (or don't count when counting cats since there is only one relevant cat alive at $t$ ). One of these parts is old looking, the other young looking. So Tibbles is old looking at $p 1$ at $t$ and young looking at $p 2$ at $t$. The perdurantist will say much the same but will not say that the two feline-looking parts of the temporal part of Tibbles at $t$ are cats. The endurantist must say that Tibbles is multi-located at $t$, and is oldlooking at $p 1$ at $t$ and young-looking at $p 2$ at $t$-where these are three-place relations between objects, places and times. 


\section{References}

Baker, L. 1997. "Why Constitution is not Identity," The Journal of Philosophy 94: $599-621$

Chisholm, R. 1986. "Intellectual Autobiography”, in Bogdan R. ed. 1986 Roderick M. Chisholm, Dordrecht: D. Reidel

Fine K. 2003. "The Non-identity of a Material thing and its Matter," Mind 112: 195 234.

Geach, P.T. 1980. Reference and Generality, $3^{\text {rd }}$ edition, Ithaca and London: Cornell University Press.

Gibbard, A. 1976. “Contingent Identity,” Journal of Philosophical Logic 4: 187 221.

Gupta, A. 1980. The Logic of Common Nouns, Yale, NH: Yale University Press. Hawley, K. 2001. How Things Persist, Oxford: Oxford University Press. Hawthorne, J. 2006. Metaphysical Essays, Oxford: Oxford University Press.

Hughes, C. 1986. "Is a Thing just the Sum of its Parts?" Proceedings of the Aristotelian Society, Supplementary Volume 85: 213 - 235.

Johnston, M. 1992. “Constitution is not Identity,” Mind, 101: 89 - 105.

-----. 2006. "Hylomorphism,” The Journal of Philosophy 102: 652 - 698.

Kripke, S. (unpublished). Lectures on Identity.

Lewis, D. 1971. "Counterparts of persons and their bodies," Journal of Philosophy

68: 203 -- 11. Reprinted in D. Lewis, 1983 Philosophical Papers, Volume I. Oxford: Oxford University Press.

-----. 1986. On the Plurality of Worlds, Oxford: Basil Blackwell.

Lowe, E. J. 2002. "Material Coincidence and the Cinematographic Fallacy:

A Response to Olson," The Philosophical Quarterly 52: 369 - 72. 
Mackie, P. 2006. How things might have been: Individuals, Kinds and Essential Properties, Oxford: Clarendon Press.

------. 2007. “Coincidence and Modal Predicates,” Analysis 67:21 -31.

------. 2008. “Coincidence and Identity,” in Royal Institute of Philosophy Supplements $83(62) 151-76$.

------. Unpublished. "Sortal Properties, Modality and Persistence"

Noonan, H. 1976. “The Four-Dimensional World,” Analysis 37: 32 -- 39.

------. 1991. “Indeterminate identity, contingent identity and Abelardian

Predicates," Philosophical Quarterly 41: 183 -- 93.

-----. 1993. “Constitution is Identity,” Mind 102:133 -- 146.

Olson, E. 2006., “The Paradox of Increase,” The Monist 89:390 - 417.

------. 2007. What are We? - A Study in Personal Ontology, New York: Oxford University Press.

Shoemaker, S. 2007. Physical Realization,Oxford: Oxford University Press.

Sider, T. 2001. Four-Dimensionalism: An Ontology of Persistence and Time,

Oxford: Oxford University Press.

Sosa, E. 1987. "Persons and other Beings," in Tomberlin J.E. ed. Philosophical Perspectives, 1, California: Ridgeview.

Stone, J. 2005a. "Why counterpart theory and three-dimensionalism are incompatible," Analysis 65: $24-27$.

-----. 2005b. "Counterpart theory and three-dimensionalism: a reply,". Analysis 65: $325-29$.

------. 2005c. "Why counterpart theory and four-dimensionalism are incompatible," Analysis 65: $329-33$.

Wiggins, D. 1967. Identity and Spatio-temporal Continuity, Oxford: Basil Blackwell. 